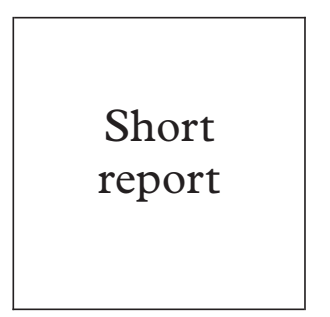

\title{
Female low sexual desire and sexually transmitted infections
}

\author{
David Goldmeier
}

Logic would suggest that women with low sexual desire do not acquire sexually transmitted infections. However, this may not be the case. Until recently, it has been considered that sexual activity in women is initiated by desire, which produces arousal. This leads to orgasm and resolution. ${ }^{12}$ In practice, sexual desire and arousal are not isolated psychological and physiological states but interdigitate and feed back on each other. In a new relationship a woman's sexual desire is often spontaneous. ${ }^{3}$ In effect this means that thoughts of her partner or seeing him are sufficient to produce an urge to want sexual relations to take place. This produces both mental excitement and bodily arousal (for example, vaginal lubrication, uterine "tenting," breast enlargement). These sensations (arousal) feed back to produce a greater desire for intercourse. However, it is also well recognised that women are less attentive to genital sensations than men, and indeed may lubricate and vasocongest in the vulva and vagina in the absence of mental sexual excitement.

The DSM IV definition of low sexual desire, or to be more precise, hypoactive sexual desire disorder is "persistently or recurrently deficient (or absent) sexual fantasies and desire for sexual activity. The judgement of the deficiencies or absence is made by the clinician, taking into account factors that affect sexual function, such as age and context of the person's life. The disturbance causes distress and interpersonal difficulty and is not accounted for by another axis I diagnosis."

In 1992 Laumann and colleagues in the United States conducted a large non-biased survey of sexual norms in men and women between the ages of 18 and 59. ${ }^{5}$ They also asked a number of simple questions relating to sexual dysfunction which the probands answered in dichotomous fashion. In all, 1749 women took part in the study. They responded in the affirmative if they had had such a problem "for one or more months over the previous year." The commonest problem was low sexual desire in women, which affected $31 \%$ of those surveyed. Sixty four per cent of these women with low desire were under 39 years of age. There was a positive correlation between low sexual desire and ever having had an STI (OR $1.44(1.02-2.03)(\mathrm{p} \leqslant 0.05)$.

In our genitourinary medicine unit a recent survey suggested that 20 out of 100 consecutively seen women were sexually dysfunctional. Seven of them complained of low sexual desire over the past year. ${ }^{6}$ All of these women were in long term relationships ( $\geqslant 9$ months), and five of the seven were diagnosed with an STI (genital herpes (one), pelvic inflammatory disease (one), trichomoniasis (one), cervicitis (one), genital warts (one)). The remaining two were appropriately concerned that they might have picked up an STI from their partner, although in fact none was found. Six of the seven women had only had sex with their long term partners, whereas one, in spite of complaining of low sexual desire for her regular partner, had had casual sex with another man in the recent past. These data might suggest that some women with low sexual desire do not want intercourse but agree to have sex with the regular partner (they didn't admit to sexual assault). It is possible that male partners of such woman need a sexual outlet outside the relationship, and that a sexually transmitted infection is later acquired by the women with low sexual desire. An alternative hypothesis is that the STI acquisition leads to low sexual desire (for example, the psychological effect of acquiring genital herpes).

How can these women with low sexual desire be helped? Initially they need to be screened for physical and psychological illness, and inquiries made of the current relationship to exclude interpersonal conflicts. However, it is likely that a large proportion of women with low sexual desire in long term relationships don't fall into any of the above categories. Both Leiblum ${ }^{7}$ and Teifer $^{8}$ feel that traditional notions of female sexual desire (for example, spontaneous fantasies) ignore many major components of women's sexual satisfaction that lead to desire - trust, intimacy, ability to be vulnerable, non-sexual touching, communication, and affection.

Rosemary Basson ${ }^{3}$ has recently redefined low sexual desire in women and has pointed out that in long term relationships women may neither have spontaneous sexual desire, nor respond mentally to genital stimulation (although they may make a genital response). These women in long term relationships have sexual desire that is responsive to emotional closeness. As she puts it "the rewards of emotional closeness-the increased commitment, bonding and tolerance of imperfections in the relationship - together with an appreciation of the subsequent wellbeing of the partner all serve as motivational factors that all activate the (desire/arousal) cycle next time." Basson's new definition of hypoactive sexual desire disorder would be " . . the persistent or recurrent deficiency (or absence) of sexual fantasies, thoughts, desire for sexual activity (alone or with a partner) and inability to respond to
Accepted for publication 17 April 2001 
sexual cues that would be expected to trigger responsive sexual desire. The symptoms need to be causing personal distress." In other words, women who have responsive sexual desire are not perceived as abnormal. This often comes as a revelation and relief to these woman and their partners.

In the United Kingdom many genitourinary medicine clinics now offer a service for patients with sexual dysfunction. ${ }^{9}$ Many women with classic sexual desire problems as well as the normal but variant responsive sexual desire patients can be helped. By doing so, STI acquisition in these patients might be prevented, although this hypothesis needs to be tested in rigorous fashion. A necessary prerequisite is government acceptance that sexual dysfunction is as much part of sexual health as STI prevention, treatment, and family planning. This would enable sexual function clinics to be properly financed and managed. Women with sexual desire problems are distressed and may have a poor quality of life, as has been shown for men with erectile dysfunction. ${ }^{10-12}$ They deserve a sympathetic hearing and optimal treatment.
1 Masters WH, Johnson VE. Human sexual response. Boston. Little Brown, 1966.

2 Kaplan HS. Hypoactive sexual desire. I Sex Marital Therapy 1979;3:3-9.

3 Basson R. The female sexual response: a different model. $\mathcal{F}$ Sex Marital Therapy 2000;26:51-65.

4 American Psychiatric Association. Diagnostic and statistical manual of mental disorders. 4th ed. Washington DC: APA, 1994.

5 Laumann EO, Paik A, Rosen RC. Sexual dysfunction in the United States. Prevalence and predictions. FAMA 1999; 281:537-44.

6 Goldmeier D, Judd A, Schroeder K. Prevalence of sexual dysfunction in new partner sexual attenders at a central London genitourinary medicine clinic in 1998. Sex Transm Inf 2000;76:208-9.

7 Leiblum SR. Definition and classification of female sexual disorders. Int f Impotence Research 1998;10:S102-6.

8 Teifer L. Historical, scientific and feminist criticisms of the "human sexual response cycle." Annu Rev Sex Res 1991;2: $1-23$.

9 Keane FEA, Carter P, Goldmeier D, et al. The provision of psychosexual services by genitourinary medicine physicians in the United Kingdom. Int 7 STD AIDS 1997;8: 402-4.

10 Aroujo AB, Durante R, Feldman HA, et al. The relationship between depressive symptoms and male erectile between depressive symptoms and male erectile
dysfunction; cross sectional results from the Massachusetts male aging study. Psychosom Med 1998;60:458-65.

11 Shabsigh R, Klein LT, Seidman S, et al. Increased incidence of depressive symptoms in men with erectile dysfunction. Urology 1998;52:848-52.

12 Litwin Ms, Nied RJ, Dhanani N. Health related quality of life in men with erectile dysfunction. $\mathcal{F}$ Gen Intern Med 1998;13:159-66. 